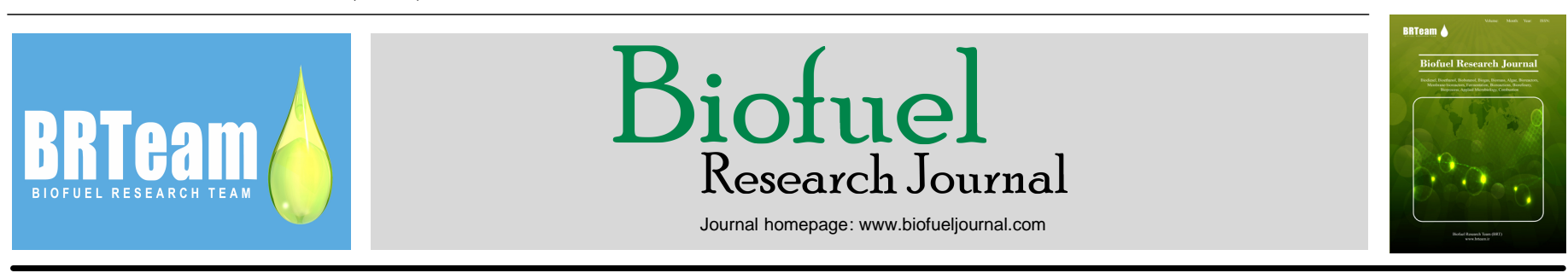

Editorial

\title{
A closer look at the developments and impact of biofuels in transport and environment; what are the next steps?
}

Nowadays, there is a worldwide interest in changing the current unsustainable economy based on fossil fuels to a more sustainable economy based on renewable biomass. Such interest is mainly motivated by the concern to reduce the emission of greenhouse gases (GHG) into the atmosphere. Biomass use for the production of fuels, chemicals, and materials is considered crucial to ensure a sustainable low-carbon economy for the future with potential environmental, economic, and social benefits. Other factors, such as the oil prices fluctuations and environmental concerns, have also made biomass an important alternative to fossil feedstocks for the production of fuels and chemicals.

The production of sustainable biofuels, in particular, has been strongly encouraged in order to reduce the GHG emissions. Petroleum is the largest contributor to carbon dioxide emissions, which in turn has a great influence on global climate change. At present, at least $60 \%$ of the world's oil is used for transportation purposes and this number is expected to increase in the next decades. As a consequence, the carbon emissions in the transport sector are estimated to increase up to $80 \%$ in 2030 . Biomass combined with carbon capture and storage is considered the only credible route to meet the GHG emission reduction targets.

Currently, not only the road transport but the entire sector of transports is committed to reducing the GHG emissions. The aviation sector, for example, aims to achieve a $\mathrm{CO}_{2}$-neutral status from 2020 onwards and expects that by 2050 its net carbon dioxide emissions will drop by $50 \%$ compared to 2005 . Renewable jet fuel, the biomass-derived alternative for fossil jet fuel, will probably be the most important contributor to reducing the carbon footprint of the aviation sector. The marine sector is also on the edge of a fueling transformation. Considering that about $90 \%$ of the world's trade is transported by ship, the total emission of $\mathrm{CO}_{2}$ from shipping is significant. In addition, maritime transport is also responsible for considerable emissions of sulfur and nitrous oxide. Therefore, this sector is also committed to promoting the use of biofuels as a sustainable, reliable, and low emissions alternative. Similar to the aviation sector, it is also estimated that the GHG emissions from shipping will drop by $40-50 \%$ in 2050 compared to 2005 . To achieve this goal, biofuels are expected to be an essential part of the future marine fuel mix.

Over the last decade, the production of renewable fuels has increased around the world due to government policies promoting the use of biofuels in the transport sector. The production of second generation ethanol on a commercial scale is already a reality. However, improvements are still needed in order to reach a more economically-competitive technology. Biomass pretreatment, for example, which is one of the most important steps to obtain an efficient conversion of biomass, is still very expensive, corresponding to approximately $18 \%$ of the total costs of the biomass conversion process. To be attractive, pretreatment must be cost-effective, operating in reactors of moderate size and with minimal heat, power, and chemical requirements. The possibility of recovering lignin for conversion to valuable products is also an important aspect to be taken into account during this stage. The high price of the enzymes used for cellulose hydrolysis is another challenge to be overcome. Although the price of the enzymes has been significantly reduced in the past years, enzymes are still expensive. In the fermentation step, the use of genetically-modified microorganisms for efficient fermentation of mixtures containing pentose and hexose sugars is also a research area that deserves attention.
Process integration is also an alternative to reduce capital costs. In this sense, different process technologies including simultaneous saccharification and fermentation (SSF) and consolidated bioprocessing (CBP), have been studied with the aim of developing more cost-effective processes for bioethanol production. The concept of CBP, which combines pretreatment, hydrolysis, and fermentation processes within a single reactor, is attractive due to the possibility of reducing operating costs, increasing conversion efficiencies, and reducing by-product inhibition. However, this technology is still far from being implemented on industrial scale and efforts have to be made in order to develop microorganisms that can both produce enzymes for the hydrolysis of biomass and then ferment the released sugars to ethanol.

In the aviation sector, major advances have been made in the production of renewable jet fuels since about 2009, but the technologies for biojet fuel production still need more research and development. The main challenge is to produce an aviation fuel that is competitive in the market, meets the strict certification requirements, and requires no changes in equipment. FischerTropsch (FT), Hydrotreated Esters of Fatty Acids (HEFA), and Synthesized Iso-Paraffins (SIP) are technologies already approved for the production of biojet fuel and there are at least other six processes currently under development to produce renewable jet fuel blending components. However, the production costs of the most cost-competive biojet fuel are still 2-4 times more expensive than petroleum jet fuel.

The maritime sector is in an early stage of orientation towards biofuels and, therefore, the use of biofuels for shipping is still no significant. However, biofuels have been considered promising options to reduce the shipping emissions. Among the options, biodiesel, for example, seems to be a good candidate as a marine fuel since it is biodegradable, non-toxic, and essentially free of sulfur. Blending a small percentage of biodiesel with marine diesel oil is considered a promising option to this sector. Recently, attention has also been paid to the use of lignin as a potential shipping fuel. In this sense, efforts have been made in order to develop a viable marine fuel from lignin that meets strict parameters on price, technical performance, sustainability, and emissions.

Overall, biofuels are promising alternatives for the road, aviation, and maritime sectors, offering potentials for a smaller carbon footprint. The main challenge is to develop production technologies that can compete with the relatively low oil prices. Furthermore, the introduction of new technologies and fuels must be performed such that safety for the personnel, infrastructure, and the environment is not compromised. Other questions that need to be addressed are related to the amount of biomass available for such application, the logistics for biomass harvesting, and supplying to the facilities, as well as the fuel distribution to the end users. If all these points are taken into account, the alternative biofuels of today may become the conventional fuels in the future.

Editor

Solange I. Mussatto Department of Biotechnology, Delft University of Technology, Delft Julianalaan 67, 2628 BC, Delft, The Netherlands

Email Address: S.I.Mussatto@tudelft.nl; solangemussatto@hotmail.com

Copyright $(92016$ Published by BRTeam

Please cite this article as: Mussatto S.I. A closer look at the developments and impact of biofuels in transport and environment; what are the next steps? Biofuel Research Journal 9 (2016) 331. DOI: 10.18331/BRJ2016.3.1.2 